\title{
Angioedema and the Canadian Network of Rare Blood Disorder Organizations: extending the Canadian hemophilia care model
}

\section{Tom Bowen}

$\infty \quad$ See related article page Io6$_{5}$

I $\mathrm{n}$ response to a push by Canadian patients with hereditary angioedema (HAE) who have recognized that the diagnosis and management of HAE was lagging behind that of many European countries (such as Italy, Hungary and Germany), ${ }^{1,2}$ Jeanne Burnham and colleagues organized a Canadian HAE patient group, the Canadian Hereditary Angioedema Society (CHAES)/Société d'angioédème héréditaire du Canada (SAHC). It met for the first time in Calgary, Alberta, in July 2002. During this meeting, a parallel was noted between HAE/CHAES and the history of hemophilia leading up to the formation of the Canadian Hemophilia Society (CHS). Steps were taken to partner with and learn from CHS.

Under the umbrella of CHS and with funding from many stakeholders (Health Canada, the Canadian Institutes of Health Research [CIHR], the Canadian Blood Services, Héma-Québec, pharmaceutical companies and organizations of patients with rare blood disorders), these groups met collectively in 2003 in Toronto, Ontario, to launch the networks of comprehensive-care clinics established to treat Canadians with rare blood disorders. ${ }^{3}$ At this meeting, international consensus was reached on an algorithm for diagnosis and case management in $\mathrm{HAE}^{4}$ The patient groups contributed much on the type and level of care that is desirable (modelled after the comprehensive care programs that exist for people with hemophilia) and supported the final consensus algorithm as coauthors.

Out of this 2003 meeting came a CHS initiative, guided by David Page: the Canadian Network of Rare Blood Disorder Organizations (NRBDO). The network comprises 7 partner organizations: the Aplastic Anemia and Myelodysplasia Association of Canada, Thalassemia Foundation of Canada, Canadian Hereditary Angioedema Society, Canadian Immunodeficiencies Patient Organization, Neutropenia Support Association Inc., Canadian Organization for Rare Disorders (CORD) and, of course, CHS. The network obtained a Sector Development Grant from the Public Health Agency of Canada's National Voluntary Health Organizations to create and coordinate a network of rare blood-disorder organizations. In addition to raising the profile of these disorders, NRBDO will work to stress the importance of key issues, including patient registries; the advantages of specialized care centres for complex, rare disorders; tracking of blood and blood products to permit inventory management and effective recall and notification procedures; active adverse-reaction reporting; and postmarketing surveillance of therapies used to treat the disorders. ${ }^{5}$ To further these objectives, an international meeting of the component organizations targeting all the NRBDO disease groups was held in Toronto in February 2006 (the proceedings from, presentations at and recommendations from the meeting are available on the CHS Web site: www .hemophilia.ca/nrbdo/en/home.php).

Health Canada initially showed support for the development of Canadian rare blood-disorder data registries that could be used in collaboration with international registries to assess and track the efficacy and effects of therapies and to permit independent assessments of phase III and IV trials. Unfortunately, this initiative has not moved forward. Since the patient populations for each disorder are small, this constitutes a real difficulty. Raising funds to develop and support registries through the more traditional routes, such as charitable donations (as has been done for disorders such as cystic fibrosis and cancer) or support from the pharmaceutical industry (for whom a product market must be large) is unrealistic. These are, indeed, orphan disorders.

\section{To date there exists no standard hemovigilance for rare blood disorders.}

Although Health Canada has established a Transfusion Transmitted Injuries Surveillance System (www.phac-aspc .gc.ca/hcai-iamss/tti-it/ttdi_e.html), it does not incorporate a hemovigilance component for patients with rare blood disorders, despite their common need and repetitive use of blood products. To date there exists no standard hemovigilance approach for people with rare blood disorders - a status similar to that for patients with hemophilia, before the Krever recommendations (available: www.hc-sc.gc.ca/ahc -asc/media/nr-cp/1998/1998_8gbk1_e.html). It is difficult to comprehend why one group like the CHS should receive comprehensive hemovigilance while those with other rare blood disorders do not. ${ }^{6}$ The standard for the CHS group should become the universal standard for any group of patients in Canada receiving blood-product replacement therapy on a regular basis. ${ }^{6}$

These registries, along with the national network of comprehensive care programs, would advance Canada greatly toward ensuring that patient care for these NRBDO groups at least equals international standards. They would also ex- 
pedite research in this area, facilitate patient participation in international studies and provide support for independent analyses to compare new therapies with current ones.

In keeping with the objective of raising awareness of the rare blood disorders, and with recognition that angioedema can be confusing because of its large overlap with the chronic urticaria-angioedema continuum and HAE, Lorenza Zingale and colleagues ${ }^{7}$ present their comprehensive-care clinic approach to angioedema without urticaria in this issue of CMAJ. They have carefully outlined a practical approach to the differential diagnosis of angioedema that should help physicians diagnose HAE much earlier than the current Io-20 years that most patients with HAE have experienced. Two further articles are planned: one on the management of HAE in children, and the other an update of the Canadian Consensus Algorithm approach to HAE.

Beyond improving the speed of diagnosis of HAE, there is much work still to be done. Similar systematic approaches are needed for the other rare blood disorders. Patient data registries and a national program of comprehensive clinics are urgently needed. At the 2006 Comprehensive Care for Rare Blood Disorders meeting, patients expressed their strong desire for these comprehensive care clinics and for home care-home therapy programs, and described what they think these clinics should look like. Patients with rare blood disorders are requesting, via NRBDO, care similar to that in provided in the CHS program, with the liberty and improved quality of life that comes with its home care-home therapy approach, standardized hemovigilance, database registry and comprehensive care approach.

This home care model is not new in Canada: the hemophilia home-care program was pioneered 33 years ago by Hanna Strawczynski's group at Montreal Children's Hospital. ${ }^{8}$ Care for those with rare blood disorders is not about inventing new models of care, but about taking what has worked so well for hemophilia and applying best practices to these other patient groups. Administrators should be interested in home therapy programs and comprehensive-care clinic approaches, which not only improve quality of life and the standard of care for patients with rare blood disorders but also remove the burden of care from emergency departments and outpatient clinics and empower these patients to control their own disorders.

One hopes Health Canada will renew its interest in improving hemovigilance for patients with these rare blood disorders, through support for database registries for each of the NRBDO disease groups. Similarly, it is hoped that each of the NRBDO groups will create, publish and regularly update evidence-based best approaches for optimizing diagnosis and management of the disorders, so that caregivers can better assist these patients, regardless of where in Canada they live.

Canada needs to wake up about other rare blood disorders and follow the superb lead of the CHS. Like all patients with serious, chronic, but more common diseases, these patients need access to high-quality, comprehensive care - not to care that is fragmented and out of date. Their lives, and their quality of living, depend on it.

Tom Bowen is Clinical Professor of Medicine and Pediatrics, University of Calgary, Calgary, Alta.

Competing interests: Tom Bowen has received consultancy fees from or been involved in educational or fundraising programs with Pharming, Jerini, Dyax-Genzyme, ZLB Behring and Kos Pharmaceuticals.

\section{REFERENCES}

I. Bowen T (guest editor). Editorial. Transfus Apher Sci 2003;29:193-4.

2. Agostoni A, Aygoren-Pursun E, Binkley KE, et al. Hereditary and acquired angioedema: problems and progress. Proceedings of the third Cr Esterase Inhibitor Deficiency Workshop and beyond. J Allergy Clin Immunol 2004;II4:S5I-I3I.

3. Bowen T, Hebert J, Ritchie B, et al. Management of hereditary angioedema: a Canadian approach. Transfus Apher Sci 2003;29:205-I4.

4. Bowen T, Cicardi M, Farkas H, et al. Canadian 2003 international consensus algorithm for the diagnosis, therapy, and management of hereditary angioedema. $J$ Allergy Clin Immunol 2004;II4:629-37.

5. Page D. Network of Rare Blood Disorder Organizations: evaluation report. 2006. Available: www.hemophilia.ca/nrbdo/en/objectives.php (accessed 2006 Sept 25).

6. Ritchie B. Tissue archives to track blood borne pathogens in people receiving blood products. Transfus Apher Sci 2003;29:269-74

7. Zingale LC, Beltrami L, Zanichelli A, et al. Angioedema without urticaria: a large clinical survey. $C M A J$ 2006;175(9):1065-70.

8. Strawczynski H, Stachewitsch A, Morgenstern G, et al. Delivery of care to hemophiliac children: home care versus hospitalization. Pediatrics 1973;51:986-9I.

Correspondence to: Dr. Tom Bowen, Medicine and Paediatrics, University of Calgary, 705 South Tower, 303I Hospital Dr. NW, Calgary AB T2N 2T8; fax 403 283-8255; tbowen@pol.net

\section{ACCESS}

$C M A J$ is the only leading general medical journal that is free online. CMAJ.ca receives over 2 million hits per month of which two-thirds are from international readers. 